\title{
DO DIFFERENCES IN PRODUCTIVITY AFFECT MOLLUSCAN FAUNAS? A PRELIMINARY TEST USING TROPICAL EASTERN PACIFIC STROMBINID GASTROPODS
}

JACKSON*, Jeremy B. C., Smithsonian Tropical Research Institute, Box 2072 Balboa, Republic of Panama; FORTUNATO, Helena, Smithsonian Tropical Research Institute, Box 2072 Balboa, Republic of Panama.

Changes in upwelling and primary productivity have been implicated as a major factor in the evolution of marine faunas. Among mollusks, differences in diversity, abundance, body size and larval development have been correlated with differences in productivity among oceans, or among different times in the same ocean. However, there have been no systematic analyses of entire faunas or clades across productivity gradients to test for significant effects. Moreover, such comparisons inevitably confound productivity with unrelated regional and historical differences that may obscure the effects of productivity per se. Thus it is necessary to examine faunal gradients within the same ocean or stratigraphic interval, as well as among different oceans and times.

Two gaps in the mountainous spine of lower Central America allow strong trade winds to blow seasonally across the Isthmus causing strong upwelling and high productivity in the Gulfs of Panama and Papagayo. In contrast, high mountains prevent such upwelling in the neighboring Gulfs of Chiriqui and Nicoya and in the Gulf of Fonseca. Thus there are two regions with very high productivity and two with lower productivity, all within the same biogeographic province. We compared the diversity, abundance, maximum size and inferred mode of development of the three principal genera of strombinid gastropods (9 Strombina, 6 Cotonopsis and 3 Sincola species) among the four regions. Available dredging and shore collections are of variable size and quality, but with no obvious biases for the taxa or parameters of interest.

There were some significant differences in abundance, maximum size and proportion of species with planktonic development among the four regions. However, none of these parameters varied consistently between the pairs of upwelling and non-upwelling regions; neither for any of the genera considered alone nor for all genera combined. Moreover, no species that occurred in two regions was restricted to only upwelling or to non-upwelling regions.

Our results are restricted to a single family of snails, and do not in any case deny the macroevolutionary importance of dramatic changes in productivity. For example, all strombinids are probably generalist predators so that diet may be a factor; or strombinids typical of low productivity regions may have all died out during the faunal turnover at the end of the Pliocene. Nevertheless, claims for the importance of productivity for molluscan distributions should be based on demonstrated differences across productivity gradients before they are used to explain macroevolutionary events. 